\title{
The shift in framing of food and beverage product reformulation in the United States from 1980 to 2015
}

Courtney Scott, MPH, RD 1

Laura Nixon, $\mathrm{MPH}^{2}$

${ }^{1}$ Faculty of Public Health and Policy, London School of Hygiene \& Tropical Medicine, 15-17

Tavistock Place, WC1H 9SH, London, UK ; Courtney.Scott@lshtm.ac.uk

2Berkely Media Studies Group, 2130 Center Street, Suite 302, Berkeley, CA 94704;

nixon@bmsg.org

\section{ACKNOWLEDGEMENTS}

The authors gratefully acknowledge Cecilé Knai, Ben Hawkins and Vanessa Ann Palzes for their help and feedback with this manuscript.

\section{DISCLOSURE}

The authors have no financial interests to disclose. 


\section{ABSTRACT}

Food and beverage product reformulation is a public health nutrition policy of recent prominence; it is a so-called 'win-win' policy, as unlike other nutrition policies it has the potential to also benefit the food and beverage industry. However, reformulation has also been criticized as being driven by industry interests. In order to inform future policy debates about reformulation, we sought to investigate how and why reformulation became a public health initiative by conducting a framing analysis on 278 U.S. newspaper articles from 1980 to 2015. Frames are aspects of text which emphasize a particular definition of a problem or solution, and were chosen as the focus of this research as they help shape policy discourses and guide which policies come onto the public policy agenda. Three primary frames of reformulation were identified: business, health and political. Having multiple frames instills reformulation with the ability to assume different meanings in different contexts, which helps to explain how it has garnered broad support from multiple sectors. The political frame of reformulation, however, only grew in importance after 2001, to describe reformulations occurring in response to public health policy initiatives aimed at obesity and noncommunicable diseases. The increasing use of a political frame, and the events described in the articles, suggest that voluntary reformulation followed a growing threat of policy change and litigation facing the industry, a finding that provides important context to debates about voluntary reformulation initiatives. Future reformulation initiatives will need to reconcile and negotiate the varying frames and aims of reformulation in order to ensure they are a success from the public health perspective.

\section{KEY WORDS}

Product reformulation; voluntary; framing; health policy; nutrition 


\section{INTRODUCTION}

While questions remain about the specific health effects of particular nutrients, ingredients and foods, the core tenets of a healthy dietary pattern are well-established: high vegetable and fruit consumption, and low consumption of foods that are high in saturated and trans fat, added sugars and salt (U.S. Department of Health and Human Services and U.S. Department of Agriculture 2015a). However, despite ample evidence and an acute need to address increasing obesity and diet-related non-communicable diseases (NCD) (Trust for America's Health and Robert Wood Johnson Foundation 2015; Beaglehole et al. 2011), policies to improve nutrition are contested in the United States (US) (Levenstein 1996; Nestle 2002; Kersh 2009).

Following the US Surgeon General's report on obesity in 2001(Office of the Surgeon General (US) et al. 2001), obesity became a central part of the public health agenda in the U.S., and therefore so too did nutrition policy (Kersh and Morone 2002). Public health nutrition policies can be divided into two general categories: those targeting consumers and their decision making, and those targeting the market environment (Brambila-Macias et al. 2011a). While policies in the market environment are likely to be more effective (BrambilaMacias et al. 2011a), nutrition policies that target the individual have historically been dominant in the US (Novak and Brownell 2012), including nutrition education, food labeling, nutrition counseling, mass media campaigns and dietary guidelines. Market environment policies place the locus of the problem with the retail and physical environments and the way they are constructed in order to influence consumers towards certain consumption and behavior patterns (Swinburn, Egger, and Raza 1999). They frequently aim to limit the availability and affordability of ultra-processed foods and beverages - main contributors to high fat, sugar and salt intake in the US and globally (Monteiro et al. 2011; Martínez Steele et al. 2016). These policies have included taxes and proposed portion size limits on sugar-sweetened beverages, and restricting where certain types of restaurants or products can be placed or sold (Brambila-Macias et al. 2011b; Sturm and Cohen 2009).

Implicit to the success of market environment policies is a population-wide decrease in consumption of ultra-processed foods and beverages, achieved through a decrease in their sales. As such, the organizations within the food industry that manufacture and sell these products are understandably concerned about the potential negative impact of these policies on their business. They have strongly opposed their incorporation into policy using a number of corporate political strategies, such as lobbying, influencing the scientific evidence base, providing funding and establishing partnerships (Mialon et al. 2016; Brownell and Warner 2009; Bailin, Goldman, and Phartiyal 2014; Scott, Hawkins, and Knai 2017).

Food and beverage product reformulation - the reduction or removal of key nutrients of concern from processed and packaged foods and beverages - is one proposed market-level solution to some of the nutrition problems in the US which has recently come into prominence (U.S. Department of Health and Human Services and U.S. Department of Agriculture 2015b). However, product reformulation differs from other market-level policies as it aims to change the nutrient profile within a product rather than decrease its 
overall consumption, and is largely supported by the food and beverage industry (Vlassopoulos et al. 2015). Indeed it is frequently undertaken in voluntary industry partnerships with health and government groups (Partnership for a Healthier America 2016; Alliance for a Healthier Generation 2016). Reformulation has also been criticized as being driven by industry interests (Scrinis 2016), in that the resulting product changes are typically small from a health perspective, but can be used beneficially in industry marketing (e.g. a product which says 'now with less sugar'). However there is limited research on the circumstances and conditions that lead to product reformulation becoming a public health policy in the US.

In order to better understand when and why reformulation emerged as the so-called 'winwin' public health nutrition policy approach, whereby both business and public health can benefit (Winkler 2013), we analyzed US newspaper articles to explore how reformulation was framed from 1980 to 2015. Media coverage of an issue influences the opinions and views of decision makers and public policy agenda setting (Scheufele and Tewksbury 2007; McCombs and Shaw 1972). In particular, how an issue is framed within the media helps shape perceptions and beliefs about what the problem is and how it should be solved (Entman 1993). Frames emphasize specific aspects of a policy issue in order to guide how and when that issue comes onto the public policy agenda, and what policy solutions are appropriate for that particular view of the problem (Mah et al. 2014; Dorfman, Wallack, and Woodruff 2005; Entman 1993). As this paper will demonstrate, food and beverage companies' reformulation efforts have generated substantial media coverage. Analyzing this coverage provides information as to the framing of food and beverage product reformulation and therefore insights into why and how reformulation became a prominent feature on the nutrition and obesity policy agenda in the US. This study is one part of a larger research project looking at the political aspects of food and beverage reformulation, in order to inform the broader debate about appropriate policy solutions to obesity and NCDs in the US

\section{METHODS}

This analysis aimed to identify how arguments about reformulation were framed in US newspaper articles from 1980 to 2015. Although online sources increasingly provide news and media for consumers in the US, newspapers remain an influential source of news, with the majority of Americans accessing newspaper content every day, either online or in print (Newspaper Association of America 2013). The newspaper articles were assessed to identify in what context arguments about reformulation appear, who is quoted in the articles and how the arguments they make about reformulation are framed, as well as the overall framing of reformulation within the article.

We searched for articles mentioning food and beverage reformulation in the top 10 newspapers in the US, as determined by their daily average circulation in March 2013, the last freely available data point from the Alliance for Audited Media (Alliance for Audited Media 2013). The searches were conducted in the Nexis database for the time period of 1 January 1980 to 8 January 2016, though not all newspapers had full text available for all years in the database (Supplementary Appendix, Table 1). In addition, full-text Wall Street 
Journal (WSJ) articles were not available in the Nexis database, and so a separate search was conducted using the search function on the WSJ website ("The Wall Street Journal" 2016). The search capabilities within the WSJ database were limited to simple searches, and required multiple smaller searches (Supplementary Appendix, Table 1).

All results from the searches were exported into Excel and checked for relevance by title or full text, as necessary. Included articles must have mentioned reformulation in the context of the nutrition, and had to be about the United States, however the overall article did not have to be about reformulation. For example, in many cases, reformulation was mentioned in the context of other nutrition policy discussions (e.g. nutrition labeling). We excluded letters to the editor and opinion pieces from the public, but included editorial board or recurring editorial columns.

From the included articles $(n=873)$ every third article (by publication date) was selected for a sample to be analyzed and coded. A smaller sample was necessary in order to enable indepth qualitative analysis. Random sampling was justified in this case because the population of articles were distributed across the days of the week (Riffe, Aust, and Lacy 1993), and the chosen random sample followed a similar distribution to that of the whole sample. From this smaller sample of articles ( $n=292), 15$ were randomly selected to be read in-depth and qualitatively analyzed (open coding) by one researcher (CS) to develop the initial coding framework specific to this study. This initial coding frame was also informed by previous studies assessing food and beverage policy framing, which have found that the industry positions themselves as "part of the solution" to obesity and NCDs, and that nutrition is frequently framed as a matter of individual responsibility (Nixon et al. 2015; Kersh 2009; Ken 2014; Jou et al. 2014). A second researcher (LN) tested the validity of this initial coding framework by applying it to a further 8 randomly selected articles, and the framework was refined accordingly. The resulting coding framework was then applied to the remaining sample of articles by one researcher (CS), however if new codes emerged through the coding process they were added to the framework iteratively. Upon coding, 14 articles were found to be irrelevant, leaving a total sample of 278 articles. The article selection process is summarized in Supplementary Appendix, Figure 1.

Three main frames of reformulation were identified and included in the coding framework: business, health and political. The key constructs and arguments underlying each of the frames are summarized in Table 1.

\section{Table 1: Frames Identified and their Underlying Constructs/Arguments}

Each sentence or paragraph that contained an argument about reformulation was coded, as well as any necessary context, and if multiple frames were present each was coded. We employed the definition of argument as put forth by Nixon et al. (2014), which "considered arguments to be specific elements that represent and express the underlying frame." From the three overarching frames (business, health, political) each article was given a primary frame, as well as a secondary frame if present. The primary frame was determined based on a number of factors within the article. These included:

- The framing of the headline

- The number of times a specific frame appeared in the article (e.g. political appeared 10 times, and business 2 times) 
- The framing of the first and last paragraphs of the article

- The 'master theme' of the article: was there an overarching narrative or theme running through the article which aligns with a particular frame?

- Who is most frequently quoted in the article (e.g. politician or company representative)?, and how are their quotes framed? Are these quotes in a position of prominence (e.g. first paragraph)?

For example, an article that primarily focused on the business aspects of reformulation but with additional discussion of the product's health impact was given a primary code of business and a secondary code of health. We also indexed the articles for stakeholders quoted, the type of reformulations described within the articles, and key events, dates, programs or individuals identified in the article.

\section{RESULTS}

Two hundred and seventy eight articles were analyzed from the period of 1 January 1983 to 8 January 2016. Although the search included dates through 1980, we did not find any articles prior to 1983. There was a peak of articles about reformulation in 1985 and again in 2015. Considering only the articles from 1997 onwards, the earliest year with results from all newspapers, the overall number of articles about reformulation appears to have gone up since 1997 (Supplementary Appendix, Figure 2).

\section{THREE PRIMARY FRAMINGS OF REFORMULATION}

\section{BUSINESS FRAMING}

The business framing of reformulation was the dominant frame in the articles analyzed, with $58 \%$ of articles $(n=162)$ having 'business' as their primary frame (Table 2).

Table 2: Framings identified in the articles

This frame was characterized by commercial drivers and inhibitors of reformulation, including impacts on sales, consumer perceptions, competitors and marketing. Most of the articles with this frame $(80 \%)$ presented reformulation as the solution to a business problem, including poor or weakening sales, increasing pressure from a competitor, changing consumer demands, increased ingredient costs or other problems with the ingredients, among others. For example:

It's not clear how far fast-food companies will go in reformulating recipes. But the nation's biggest chains face growing competition. In the latest quarter, customer visits to traditional fast-food hamburger chains declined 3 percent from a year ago, according to market researcher NPD Group. Fast-casual chains saw visits rise 8 percent. (Choi 2015)

In this framing, reformulation frequently represented a sales or business opportunity. This included invoking a sense of 'gold rush' fervor and presenting reformulation as a means of overtaking a competitor. For example:

Food companies are racing to produce new and improved fat-reduced and fat-free products. (Webb 1990) 
As the above quote demonstrates, the business framing of reformulation did not exclude discussions of nutrition or health, however in this framing the primary purpose of reformulation was to present a solution to a business problem or a new business opportunity. Nutrients may have been referenced in relation to the reformulation, but the ultimate goal of the reformulation was business related. For example:

Sometimes food companies even eke out marketing advantages by responding to health concerns, as ConAgra Foods did with its Healthy Choice line during the fitness-crazed 1990s. (Greising 2003)

Mayonnaise is a $\$ 650$ million business that has been slowly declining, partly because of cholesterol fears...the new product may put the mayonnaise back in a lot of sandwiches. (Kleinfield 1989)

Business arguments against reformulation were less frequent (33\% of articles), and included that it was a risk to sales and that there were significant costs, in time and efforts, involved in successful reformulations, among others, as demonstrated by these quotes:

...research and development costs have risen 35 percent in the last five years as the company concentrated on developing news cereals for nutrition-conscious adults. (Key 1989)

In 1990,14\% of food product launches were low sodium, according to Marketing Intelligence Services, a research firm that tracks product launches. But the products rarely sold well as food companies struggled to find workable salt substitutes. (Ellison 2005a)

\section{Health Framing}

The health framing of reformulation primarily positioned reformulation as a solution to a health-related problem, including obesity or excessive intake of particular nutrients of concern, and was the primary framing in $22 \%(n=62)$ of articles. A typical health-framed view on reformulation is demonstrated by this quote:

A medium-size popcorn and medium soft drink at the nation's largest movie chains pack the nutritional equivalent of three Quarter Pounders topped with 12 pats of butter, according to a review released Wednesday by the consumer advocacy group Center for Science in the Pubic Interest. The group's second look at movie theater concessions...found little has changed in the last decade-and-a-half, despite some moves by movie theaters to reformulate. (MacVean 2009)

This framing is often presented within a narrative about the poor or declining health of Americans, or as a solution to the problem of unhealthy food and beverage products. For example:

The issue is especially important because, as participants made clear, Americans are still eating far too much fat. (Webb 1990)

In the health frame, the primary purpose of reformulation is to solve or respond to a health problem, though business and political arguments were often used alongside. For example: 
The latest U.S Dietary Guidelines released in January advise eating three 1-ounce servings of whole grains each day...Cereal companies responded aggressively.

(Deardorff 2005)

Health arguments made against reformulation included that it can result in misleading marketing about the healthfulness of a product, and that reformulation does not necessarily mean a product is healthy. For example:

Cracklin' Oat Brain seems to have been the single product that most outraged Sokolof. 'The consumer is buying oat bran to lower his cholesterol and he's ingesting coconut oil, which is raising his cholesterol,' he says. 'It's a deception.' (Streitfeld 1989)

Whole grain products aren't automatically higher in fiber. Often, the higher the sugar, the lower the fiber... (Deardorff 2005)

Another health-framed argument against reformulation was that reformulation targets the nutrient that is of concern today, rather than focusing on the overall health profile of the products. As the quotes below illustrate, health arguments against reformulation also implied a tension between the importance of specific nutrients at different points in time. For example:

Companies have been working to reformulate products...[But] many processed foods are still high in saturated fat, sodium and added sugars...(The Washington Post 2008)

Still, some nutritionists now worry that the focus on trans fats will lead people to lose sight of saturated fats. (Abboud 2003)

\section{Political Framing}

The third framing of reformulation was the political framing, in which reformulation is part of a policy discussion, and seen as a solution to the problem of needing to implement obesity and NCD policies. One-fifth of articles $(n=54)$ had this as their primary framing.

This included positioning reformulation as a response to policy decisions such as nutrition labeling changes, or as a means for the industry to avoid negative outcomes from policy decisions. For example, this article described reformulation as a response to mandatory trans fat labeling laws:

In 2006, The F.D.A. required companies to list trans fat on nutrition labels, a shift that prompted many producers to eliminate them. That year, New York City banned trans fats in food sold by restaurants and bakeries; other places, including California, Cleveland and Philadelphia, followed suit. Many major chains, including McDonald's, found substitutes that sharply reduced or eliminated trans fats, as did Crisco. (Tavernise 2015)

Other articles positioned reformulation as a response to the industry being criticized by policymakers and nutrition advocates for the nutrition profile of their products. For example: 
Several sectors of the food industry, including packaged-food makers and fast-food restaurants, have come under fire over the years regarding calorie counts and nutrition. A number of companies in recent years have moved to improve the nutrition content of their products, including reductions in sugar and salt content. (Kell 2010)

The political framing also encompassed reformulations that arose in order to comply with, or change in advance of, federal regulations on health claims and labeling on food and beverage packages. For example:

With a new food-labeling law set to take effect Jan.1...Some big food makers like Campbell Soup Co. are going so far as to revamp their recipes to take out allergens before they are required to list them. (Zhang 2005)

Reformulation was frequently framed politically in articles about the governments attempts to set voluntary standards for products that can be marketed to children. Following the release of proposed voluntary standards - which ultimately were never finalized - the food and beverage industry responded by creating their own voluntary standards for marketing to children, and reformulating products to meet their own standards ahead of the government standards. For example:

...The Obama administration in April proposed voluntary nutritional standards for foods marketed at kids and teens...CFBAI members responded with their own uniform food-specific guidelines for food marketing...though the New York Times noted that only one-third of the companies' advertised products would have to be reformulated to meet the standards. (Hobson 2011)

Furthermore, the political framing was associated claims of responsibility, particularly directed at the industry.

With two-thirds of Americans considered overweight or obese, reformulation is part of the industry's response to lawmakers, nutritionists and lawyers who say food companies deserve a super-size portion of the blame. (Zitner 2004)

This framing of reformulation also brought in overtly political discussions about politicians and policies, about policy compromises and power struggles, and the position of the industry in the policy process. For example:

Thursday's guidelines are the latest in a series of federal efforts to prod food makers to offer healthier products. Advocates have centered their efforts of voluntary guidelines, viewing outright bans on marketing of unhealthy foods as unlikely to win federal approval. (Adamy 2011)

In particular, the Obama administration and Michelle Obama specifically, featured prominently in politically framed articles, with her Let's Move program being cited as an impetus for reformulation. For example:

Wal-mart, the nation's largest retailer, will announce a five-year plan on Thursday to make thousands of its packaged foods lower in unhealthy salts, fats and sugars....The 
initiative came out of discussions the company has been having with Michelle Obama, the first lady, who will attend the announcement in Washington... (Stolberg 2011)

\section{PERIODIC TRENDS}

From 1983 to 2000, the articles were primarily framed in terms of business arguments $(\mathrm{n}=88)$, with a smaller number of articles having a primary health framing $(\mathrm{n}=15)$. Only nine of $112(13 \%)$ articles in this period had a primary political framing (Figure 3). In the period from 2001 to 2015, the political framing of reformulation became more frequent, with 44 of 166 articles (26.5\%) being primarily framed in this way; health framing also increased $(n=47)$ but business framing remained predominant $(n=77)$.

Figure 1: Primary Frame by Year

Coinciding with an increase in the political framing of reformulation, the period from 2001 to 2015 was characterized by a repeated pattern of policy change and/or litigation efforts against the food industry, followed by an announcement of voluntary reformulation efforts on the part of the industry. As such, politically framed articles appeared clustered around political events. Of the 82 articles coded with a primary or secondary political frame, 63 described the reformulation as following a specific policy or legal action (77\%). Of those, 37 were prompted by a federal policy debate or change, 14 by a state or local government policy debate or change, 7 by the introduction of a lawsuit against the company, and 5 by Michelle Obama's Let's Move campaign. In particular, the years with peak political framing as the primary framing in the article - 2005 and 2011-coincided with major nutrition policy actions by the federal government: in 2005 the FDA announced plans to adopt mandatory trans fat labeling; in 2011 the government discussed standards for marketing food and beverage products to children, and Michelle Obama's Let's Move Campaign announced joint efforts with Wal-Mart and the National Restaurants Association.

The rise of political framing of reformulation in this period was also associated with a change in food and beverage industry strategy, moving from denying their potential role in the obesity epidemic to acknowledging their desire to be 'part of the solution' to obesity. For example, in 2003 McDonalds denied "that [the] current concern of fast rising rates of obesity" was behind their decision to reformulate their Chicken McNugget"(Alexander 2003). However, the article goes on to say "the launch is well-timed for McDonald's, which recently has come under especially harsh criticism on the healthiness of its food," and describes how the reformulation follows a lawsuit against the company:

The company this year secured the dismissal of a high-profile lawsuit in New York that accused McDonald's food of causing obesity in two children, but not before the judge opined that McNuggets were a "McFrankenstein creation of various elements not utilized by the home cook. (Alexander 2003)

Whereas in contrast, later articles featured discussions of 'being part of the solution.' For example, a Los Angeles Times opinion piece in 2003 opened by saying:

For the last year, the packaged food industry has been getting a good old-fashioned cuffing....Politicians in Sacramento and elsewhere have been legislating furiously to ban snack foods in schools...Yet until recently, the response of Big Food has been 
largely defensive...That changed this month when Kraft Foods Inc.,...announced a wide-ranging series of anti-obesity initiatives: smaller individual portion sizes, an end to marketing in public schools, even reformulation of some of its more egregious artery-cloggers....(Crister 2003)

Another article discussed how not taking action became a bigger political risk to the industry, and compared the situation to the tobacco industry:

Kraft felt inaction might invite a greater threat. The government could impose restrictions on children's marketing, not to mention the risk of bad publicity or potential lawsuits. 'If the tobacco industry could go back 20 or 30 years, reform their marketing, disarm their critics, and sacrifice a couple of hundred million in profits, knowing what they know today, don't you think they'd take that deal in a heartbeat?' asked Michael Mudd, an architect of Kraft's obesity strategy and a form executive vice president...(Ellison 2005b)

However, there was a tension in the articles between reformulation and the industry being 'part of the solution' and using reformulation as an argument against other nutrition policies. For example, in an article on the proposed standards on marketing to children, an industry group said they had already reformulated, implying that the new standards are not necessary:

Food makers already cut back on marketing some of their least healthful products to kids amid pressure from regulators and the threat of lawsuits. The Grocery Manufacturers Association says that in recent years food and beverage manufacturers have changed the recipes of more than 20,000 products to reduce calories, sodium, sugar and fat. The association recently agreed to place nutrition information on the front of package. (Kilman 2011)

This same argument was also present a few years before against proposed regulations from the FDA on nutritional claims on packages (Zhang 2009), and in the context of Michelle Obama's Let's Move campaign:

Food makers, which have fended off other government attempts for new nutrition regulations, say they have already made changes to combat childhood obesity by curbing marketing to children and offering healthier options. The Grocery Manufacturers Association...said its members have reformulated 10,000 products in recent years to reduce levels of calories, fat and sodium. (Adamy 2010)

Likewise, there was a tension between reformulation being 'part of the solution' (political framing) and it being a response to consumer demand (business framing). In an article about the FDA setting a deadline for the industry to remove trans fats from products, the industry rationale in reformulating was described as being "cognizant of consumer demand" and responding to "research about the harm caused by trans fat" (Tavernise 2015). Or, for example, this article which described the reformulations as being motivated by both consumer demand and policy change:

As consumers increasingly ask for healthier fare, the company that operates Olive Garden and Red Lobster restaurants said Thursday that it will cut salt and calories across its menus by 10 percent over the next five years and 20 percent over the next 
decade...The move comes as the federal government and some states have stepped up pressure on the nation's restaurants to post calorie information...(Bryson York 2011)

In the post 2001 period, health arguments against reformulation centered on it being a minor change to products that are otherwise "just not redeemable" (Zitner 2004). These arguments typically appeared towards the end of the articles, after the industry reformulation announcement or effort had been discussed, indicating their relatively weaker position within the articles. Articles with a primary political framing also frequently discussed the business implications of a policy or legal challenge facing the industry. However, the business arguments were stated in response to the policy or reformulation effort.

The analysis also found a periodic trend in the target or focus of the reformulations, becoming more nutrient focused as time went on, which aligns with the framing trends (Supplementary Appendix, Figure 3). In the period from 1983 to 2001, which was primarily business framed, the majority of reformulations were undertaken to improve non-nutrient qualities of the products (e.g. taste, texture, etc). Reformulations to reduce saturated fat and cholesterol were also prevalent in this period, but to a lesser extent. In contrast, the period from 2001 to 2015, which was associated with a rise in political and health framing, the reformulations were increasingly targeting specific nutrients or multiple nutrients (e.g. salt, sugar, and fat), as well as other ingredients that had gained a negative public perception (e.g. additives, GMOs, artificial sweeteners and gluten).

\section{FRAMING BY STAKEHOLDER GROUP}

Industry actors were the most frequently quoted stakeholder group, appearing in over half of the articles analyzed ( $n=148)$, followed by those from public health groups $(n=64)$. Actors from other sectors were less prominent in the articles analyzed (Academia=27, Government $=28$, Other $=25$, General public $=9$ ). Across all three primary framings, an average of $51 \%$ of frames identified came from general text of the author, rather than quotes attributed to specific actors. Articles with a primary frame of business featured four times as many quotes from industry actors as from government, public health and academia combined ( $n=201$ v. $n=49$ ).

\section{DISCUSSION}

From 1980 to 2015 food and beverage product reformulation was framed in US newspaper articles as a solution to three types of problems: business, health or political. The business and health framings of reformulation appeared consistently throughout the sample analyzed, while the political framing appeared only sporadically as a secondary framing until 2001, when it became a recurrent primary framing. The three framings, however, were not mutually exclusive, with health and business arguments featuring alongside the political framing and vice versa.

In the 1980s and 1990s, the articles primarily described reformulation as a business initiative, even when prompted by health fads or trends, with reformulations frequently targeting the sensory characteristics of the product and with the goals of sales growth and 
outperforming competition. Starting in the 2000s and continuing in to the 2010s, when litigators and the government began to focus on the causes of obesity and diet-related diseases, there was a marked shift in the tone of the articles and reformulation became framed as a policy-related initiative with specific health goals. This analysis suggests that reformulation has evolved over time from an internally driven process responding to a business opportunity, to being a response to an externally driven political or public relations threat. These two conditions, however, are not mutually exclusive, and the political threat has not replaced traditional business threats but rather added to them.

From 2001 to 2015, the industry frequently framed reformulation initiatives as being voluntary and in response to consumer demand, while the articles repeatedly included background text about recent lawsuits or government policy changes facing the industry. Multiple articles referred to the industry as being "under fire" and threatened by policy and legal action. However, by acting voluntarily ahead of proposed regulatory changes, the food and beverage company's actions were positively received in the articles and generated positive PR for the company, as well as directly heading off specific litigation attempts against the industry on multiple occasions. The business roots of reformulation, however, were still prevalent even in the most recent articles, and the predominance of a business frame shaped the portrayal of reformulation as a business initiative that has public health benefit (rather than as a public health initiative itself). Collectively, the articles described reformulation as a business response to a threat, whether that threat be their competitor, weakening sales, or in the later years the government. The focus on a business frame also emphasizes the cost and effort to business in reformulating, and the prominence given to consumer demand within the articles suggests it is an important deciding factor for the food and beverage industry in whether or not to a undertake reformulation.

In the public health field, there are on-going debates about the merit of voluntary and selfregulated food and beverage industry initiatives, and this finding - that voluntary reformulation followed increased political pressure on the industry - provides important context for that debate. Proponents argue that voluntary agreements are more expedient and effective than pursing a difficult regulatory course of action (Haufler 2001; Institute of Medicine 2012). However, given the emphasis the industry places on the difficulties and length of time needed to undertake reformulation - in this analysis and others (Webster et al. 2011; National Heart Foundation of Australia 2012) - it is unlikely that they would have taken such voluntary reformulation actions if the threat of policy change were not already present in the early 2000s. Furthermore, these findings align with previous research showing that the food and beverage industry has shifted their framing of obesity overtime to encompass being 'part of the solution' (Nixon et al. 2015). Moreover, although we recognize it is not possible to directly compare the tobacco and food industries, previous research on the tobacco industry mirrors and supports the results of this analysis. In the case of tobacco, the industry created and promoted filtered and low-tar/low-nicotine cigarettes following increasing pressure from the public and policy makers in the 1940's, 50s and 60s (Hurt and Robertson 1998; Warner 1985).

This analysis begins to provide insights into how and why reformulation has become a prominent public health policy. It is a topic that, over time, has combined the business and profit interests of food and beverage companies, with the health interests of public health 
actors, and the policy interests of government. It is a "chameleonic idea": one that can appeal to multiple actors from multiple viewpoints (Smith 2013). It is seen as a 'win-win' for addressing the problems of obesity and NCDs without heavily infringing on the business practices of the food and beverage industry. However, the competing framings identified in this analysis demonstrate the tensions that come with integrating business, health and political interests into a single idea. Arguments made in the health framing of reformulation describe the health status of Americans as poor or failing -a 'story of decline' (Stone 2012)and actors making these arguments suggest that more significant changes to products and the food environment are required. Whereas arguments made in the business frame describe small-scale changes to existing products, so as not to threaten profitability, but which generate positive PR and improve brand image. As the purpose of reformulation has shifted from a purely business initiative to one with a political intention, the political frame of reformulation has become and will remain important. Reconciling and negotiating these frames and aims of reformulation will be a necessary step in ensuring its success from the public health point of view.

\section{Limitations}

This is only one illustration and does not claim to explain causation between the sequence of events described in the articles and the framings of reformulation. It is limited by its singular focus on newspaper articles in the United States, and that the newspapers analyzed had varying years available in the databases used. In particular, that articles covering reformulation appear to have risen over time may be due to the limited availability of older articles in the database or the sampling method of selecting every third article, which may have inadvertently made the prevalence of articles appear higher in certain years over others. Each of the three frames found in the articles analyzed could reflect reporting styles of the various newspapers, of the section the article was found in, or the specific journalist. However, taken together, and in the context of the temporal trends identified, the sample analyzed suggests that the framing of product reformulation has shifted.

\section{REFERENCES}

Abboud, Leila. 2003. "The Truth About Trans Fats: Coming to a Label Near You." Wall Street Journal, July 10.

Adamy, Janet. 2010. “First Lady Girds to Fight Fat.” Wall Street Journal, February 9.

Adamy, Janet. 2011. “Tough New Rules Proposed on Food Advertising for Kids.” Wall Street Journal, April 29.

Alexander, Delroy. 2003. “McNugget Makeover.” Chicago Tribune, October 5.

Alliance for a Healthier Generation. 2016. "Take Action: Industry.” Accessed February 3. https://www.healthiergeneration.org/take_action/industry/.

Alliance for Audited Media. 2013. “Top 25 U.S. Newspapers for March 2013.” http://auditedmedia.com/news/research-and-data/top-25-us-newspapers-formarch-2013/.

Bailin, Deborah, Gretchen Goldman, and Pallavi Phartiyal. 2014. Sugar-Coating Science. 
Beaglehole, Robert, Ruth Bonita, Richard Horton, Cary Adams, George Alleyne, Perviz Asaria, Vanessa Baugh, et al. 2011. "Priority Actions for the Non-Communicable Disease Crisis.” The Lancet 377 (9775): 1438-1447.

Brambila-Macias, J, B Shankar, S Capacci, M Mazzocchi, F J Perez-Cueto, W Verbeke, and W B Traill. 2011a. "Policy Interventions to Promote Healthy Eating: A Review of What Works, What Does Not, and What Is Promising." Food Nutr Bull 32 (4): 365-375.

Brambila-Macias, J, B Shankar, S Capacci, M Mazzocchi, F J Perez-Cueto, W Verbeke, and W B Traill. 2011b. "Policy Interventions to Promote Healthy Eating: A Review of What Works, What Does Not, and What Is Promising." Food Nutr Bull 32 (4): 365-375.

Brownell, K D, and K E Warner. 2009. "The Perils of Ignoring History: Big Tobacco Played Dirty and Millions Died. How Similar Is Big Food?" Milbank Q 87 (1): 259-294. doi:10.1111/j.1468-0009.2009.00555.x.

Bryson York, Emily. 2011. "Healthy Fork in the Road: Owner of Olive Garden, Red Lobster Will Trim Salt, Calories of Menu Items by 20 Percent during the next Decade." Chicago Tribune, September 16.

Choi, Candace. 2015. "Fast-Food Chains Seek Fresh Image; Updates Could Include Fewer Preservatives." Chicago Tribune, January 5.

Crister, Greg. 2003. “Big Food's Aisles of Excess.” The Los Angeles Times, July 20.

Deardorff, Julie. 2005. “Where's the Fiber?; In Wholegrain Cereals, Numbers Don't Always Add up to 'Healthy.'” Chicago Tribune, March 20.

Dorfman, Lori, L Wallack, and K Woodruff. 2005. "More Than a Message: Framing Public Health Advocacy to Change Corporate Practices." Health Education and Behavior 32 (3): 320-336.

Ellison, Sarah. 2005a. “Despite Big Health Concerns, Food Industry Can’t Shake Salt.” Wall Street Journal, February 25.

Ellison, Sarah. 2005b. "Kraft Ad Shift Shakes up Food World: Facing Heat on Obesity, Firm Limits Advertising Aimed at Kids under 12." Chicago Sun Times, November 6.

Entman, Robert M. 1993. "Framing: Toward Clarification of a Fractured Paradigm." Journal of Communication 43 (4). Blackwell Publishing Ltd: 51-58. doi:10.1111/j.14602466.1993.tb01304.x.

Greising, David. 2003. "3-Year Plan May Fuel Slow Burn against Big Food.” Chicago Tribune, July 11.

Haufler, Virginia. 2001. A Public Role for the Private Sector: Industry Self-Regulation in a Global Economy. Washington D.C.: Carnegie Endowment for International Peace.

Hobson, Katherine. 2011. “Progress, Not Perfection, on Reducing Kids' Exposure to Ads for Unhealthful Foods.” Wall Street Journal, August 2.

Hurt, Richard D, and Channing R Robertson. 1998. "Prying Open the Door to the Tobacco industry\&\#39;s Secrets about Nicotine: The Minnesota Tobacco Trial." JAMA 280 (13): 1173-1181.

Institute of Medicine. 2012. Building Public-Private Partnerships in Food and Nutrition: 
Workshop Summary. Edited by Leslie Pray and Laura Pilsbury. Washington, DC: The National Academies Press. doi:10.17226/13412.

Jou, Judy, Jeff Niederdeppe, Colleen L Barry, and Sarah E Gollust. 2014. “Strategic Messaging to Promote Taxation of Sugar-Sweetened Beverages: Lessons from Recent Political Campaigns." American Journal of Public Health 104 (5). United States: 847-853. doi:10.2105/AJPH.2013.301679.

Kell, John. 2010. "Pepsi, Coke Support Calorie-Labeling Effort.” Wall Street Journal, February 10.

Ken, Ivy. 2014. "A Healthy Bottom Line: Obese Children, a Pacified Public, and Corporate Legitimacy.” Social Currents. doi:10.1177/2329496514524927.

Kersh, Rogan. 2009. "The Politics of Obesity: A Current Assessment and Look Ahead." Milbank Quarterly 87 (1). Blackwell Publishing Inc: 295-316. doi:10.1111/j.14680009.2009.00556.x.

Kersh, Rogan, and James Morone. 2002. "The Politics Of Obesity: Seven Steps To Government Action." Health Affairs 21 (6): 142-153. doi:10.1377/hlthaff.21.6.142.

Key, Janet. 1989. “Rising Costs May Be Ending Food Industry's Life in the Fat Lane.” Chicago Tribune, February 26.

Kilman, Scott. 2011. "Tough New Rules Proposed on Food Advertising for Kids.” Wall Street Journal, April 29.

Kleinfield, KR. 1989. “Catching the Anti-Cholesterol Fever.” New York Times, April 16.

Levenstein, Harvey A. 1996. "The Politics of Nutrition in North America." Neuroscience \& Biobehavioral Reviews 20 (1): 75-78. doi:http://dx.doi.org/10.1016/01497634(95)00036-E.

MacVean, Mary. 2009. "Movie Popcorn Equals Three Quarter Pounders?" Chicago Tribune, November 19.

Mah, Catherine L, Catherine Hamill, Krista Rondeau, and Lynn McIntyre. 2014. "A FrameCritical Policy Analysis of Canada's Response to the World Food Summit 1998--2008." Archives of Public Health 72 (1): 1-7. doi:10.1186/2049-3258-72-41.

Martínez Steele, Eurídice, Larissa Galastri Baraldi, Maria Laura da Costa Louzada, JeanClaude Moubarac, Dariush Mozaffarian, and Carlos Monteiro. 2016. "Ultra-Processed Foods and Added Sugars in the US Diet: Evidence from a Nationally Representative Cross-Sectional Study." BMJ Open 6 (3). doi:10.1136/bmjopen-2015-009892.

McCombs, Maxwell E, and Donald L Shaw. 1972. "The Agenda-Setting Function of Mass Media." Public Opinion Quarterly 36 (2): 176-187. doi:10.1086/267990.

Mialon, Melissa, Boyd Swinburn, Steven Allender, and Gary Sacks. 2016. "Systematic Examination of Publicly-Available Information Reveals the Diverse and Extensive Corporate Political Activity of the Food Industry in Australia." BMC Public Health 16 (1): 1-13. doi:10.1186/s12889-016-2955-7.

Monteiro, Carlos, R B Levy, R M Claro, I R de Castro, and G Cannon. 2011. “Increasing Consumption of Ultra-Processed Foods and Likely Impact on Human Health: Evidence 
from Brazil." Public Health Nutr 14 (1): 5-13. doi:10.1017/s1368980010003241.

National Heart Foundation of Australia. 2012. Rapid Review of the Evidence: Effectiveness of Food Reformulation as a Strategy to Improve Population Health.

Nestle, M. 2002. Food Politics: How the Food Industry Influences Nutrition and Health. Berkeley and Los Angeles, California: University of California Press.

Newspaper Association of America. 2013. "Across Platforms, 7 in 10 Adults Access Content from Newspaper Media Each Week.” http://www.naa.org/Trends-andNumbers/Readership.aspx.

Nixon, Laura, Pamela Mejia, Andrew Cheyne, Cara Wilking, Lori Dorfman, and Richard Daynard. 2015. "'We're Part of the Solution': Evolution of the Food and Beverage Industry's Framing of Obesity Concerns Between 2000 and 2012." American Journal of Public Health 105 (11). United States: 2228-2236. doi:10.2105/AJPH.2015.302819.

Novak, Nicole L, and Kelly D Brownell. 2012. "Role of Policy and Government in the Obesity Epidemic." Circulation 126 (19): 2345-2352. doi:10.1161/CIRCULATIONAHA.111.037929.

Office of the Surgeon General (US), Office of Disease Prevention and Health Promotion (US), Centers for Disease Control and Prevention (US), and National Institutes of Health (US). 2001. The Surgeon General's Call to Action to Prevent and Decrease Overweight and Obesity. Rockville, MD: Office of the Surgeon General (US).

Partnership for a Healthier America. 2016. "About The Partnership.” Accessed February 3. http://ahealthieramerica.org/about/about-the-partnership/.

Riffe, Daniel, Charles F Aust, and Stephen R Lacy. 1993. "The Effectiveness of Random, Consecutive Day and Constructed Week Sampling in Newspaper Content Analysis." Journalism Quarterly 70 (1). SAGE Publications: 133-139. doi:10.1177/107769909307000115.

Scheufele, Dietram A, and David Tewksbury. 2007. "Framing, Agenda Setting, and Priming: The Evolution of Three Media Effects Models." Journal of Communication 57 (1): 9-20. doi:10.1111/j.0021-9916.2007.00326.x.

Scott, C, B Hawkins, and C Knai. 2017. "Food and Beverage Product Reformulation as a Corporate Political Strategy.” Social Science \& Medicine 172 (1-2): 37-45. doi:10.1016/j.socscimed.2016.11.020.

Scrinis, Gyorgy. 2016. "Reformulation, Fortification and Functionalization: Big Food Corporations' Nutritional Engineering and Marketing Strategies.” The Journal of Peasant Studies 43 (1): 17-37. doi:10.1080/03066150.2015.1101455.

Smith, Katherine. 2013. Beyond Evidence-Based Policy in Public Health: The Interplay of Ideas. Basingstoke, Hampshire: Palgrave Macmillan.

Stolberg, Sheryl Gay. 2011. "Wal-Mart Takes a Healthy Turn.” New York Times, January 20.

Stone, Deborah A. 2012. Policy Paradox: The Art of Political Decision Making. New York, NY: W.W. Norton.

Streitfeld, David. 1989. “Consummate Consumer;A Millionaire Crusader’s Food Fight.” USA 
Today, January 5.

Sturm, Roland, and Deborah A Cohen. 2009. "Zoning for Health? The Year-Old Ban on New Fast-Food Restaurants in South LA." Health Affairs 28 (6): w1088-97. doi:10.1377/hlthaff.28.6.w1088.

Swinburn, B, G Egger, and F Raza. 1999. "Dissecting Obesogenic Environments: The Development and Application of a Framework for Identifying and Prioritizing Environmental Interventions for Obesity." Prev Med 29 (6 Pt 1): 563-570. doi:10.1006/pmed.1999.0585.

Tavernise, Sabrina. 2015. "F.D.A. Sets 2018 Deadline to Rid Foods of Trans Fats." New York Times, June 17.

“The Wall Street Journal." 2016. Accessed March 22. www.wsj.com.

The Washington Post. 2008. "Making Headway or Headed Nowhere?" The Washington Post, May 19.

Trust for America's Health, and Robert Wood Johnson Foundation. 2015. The State of Obesity: 2015.

U.S. Department of Health and Human Services and U.S. Department of Agriculture. 2015a. Dietary Guidelines for Americans 2015. 8th Edition.

U.S. Department of Health and Human Services and U.S. Department of Agriculture. 2015b. "Opportunities to Align Food Products and Menus with the Dietary Guidelines." In 2015-2020 Dietary Guidelines for Americans, 8th Editio. Washington, DC.

Vlassopoulos, Antonis, Gabriel Masset, Fabienne Leroy, and Jorg Spieldenner. 2015. "Industry Approach to Nutrition-Based Product Development and Reformulation in Asia." Journal of Nutritional Science and Vitaminology 61 Suppl: S187-8. doi:10.3177/jnsv.61.S187.

Warner, Kenneth E. 1985. "Tobacco Industry Response to Public Health Concern: A Content Analysis of Cigarette Ads." Health Education \& Behavior 12 (1): 115-127. doi:10.1177/109019818501200111.

Webb, Densie. 1990. “Eating Well.” New York Times, October 24.

Webster, Jacqueline L, Elizabeth K Dunford, Corinna Hawkes, and Bruce C Neal. 2011. "Salt Reduction Initiatives around the World." Journal of Hypertension 29 (6): 1043-1050. doi:10.1097/HJH.0b013e328345ed83.

Winkler, J T. 2013. “Brutal Pragmatism on Food.” BMJ 346. doi:10.1136/bmj.f3728.

Zhang, Jane. 2005. "How Much Soy Lecithin Is in That Cookie?” Wall Street Journal, October 13.

Zhang, Jane. 2009. "FDA Targets Nutritional Claims on Food Packaging.” Wall Street Journal, October 20.

Zitner, Aaron. 2004. "Lab Reformulates Food in Battle against Obesity." Chicago Tribune, January 22. 